\title{
In praise of clozapine
}

Jacqualline M. Atkinson revilews 'Out of Darkness': Odyseoy Video, 1994

Diana Ross probably isn't most people's idea of the actress to cast as someone with chronic mental illness, yet in Out of Darkness she plays 42-year-old Pauline Cooper, a "paranoid schizophrenic'.

This made-for-American television fllm starts predictably: tablets washed down the sink, Pauline behaving oddly in public, and being picked up by the police. It comes as no surprise that she is seen shouting and thrashing around while strapped into a wheelchair before being taken to a locked ward. Her violent outbursts are supplemented by classic symptoms: she can't control her thoughts, hears voices and is deluded. Her mother sums up our feelings; "It is as though she has a terminal illness, except she never dies."

This sets the scene for a film which crams as many stereotypes as possible into its 88 minutes: the young daughter, worried she might develop schizophrenia, raised by her grandmother; the sister jealous of their mother's attention; the mother who sleeps with the granddaughter in a locked room. After recovery, there is the boyfriend who cannot accept her former illness, the mother who can't relinquish her caring role and the daughter who doesn't want to live with her.

But this is a film about hope, and hope comes via clozapine. It is presented almost as a prize: "Clozapine isn't avallable to everyone with schizophrenia. You have to have falled on two other neuroleptics or have severe tardive dyskinesia." Her mother sees hope held out and then taken back when she is told of the side effects.

Pauline moves into a residential rehabilitation centre which emphasises the costs of the American health care system; her mother pays $\$ 3,800$ per month to keep her there. That it is well worth it is indicated by her return to her former self, an event which seems to occur in an instant while sitting in the park, the sun predictably glinting through the trees as the inevitable children play and young lovers kiss. "I'm back", she tells her mother on the telephone, "I'm saved". It is not all plain sailing towards the mawkishly sentimental ending but Pauline sums it up: "I have my life back - or have a life again."

What does this film tell us about schizophrenia? We are given a dramatic portrayal of the positive symptoms but learn little of the chronic, negattve symptoms that inhibit recovery. There is an emphasis on the genetic; stress is mentioned only in passing and the impact of family environment not at all. There is no account of psychosocial interventions. Pauline's continued progress is apparently due entirely to clozapine. The drug is the answer.

Whatever we feel about this as a message we should not overlook the significance of the 'happy ending. Other similar films have been less posittve. The 1985 film, Promise, also made for American television, starred James Garner and won five Emmy and two Golden Globe awards. A promise to care for his schizophrenic brother finishes with only a vague message of hope as the brother agrees to move into a residential home where he may be less isolated than he is at home. Can You Hear Me Thinking, a 1990 BBC production starring Judi Dench and Michael Williams as the parents, ends with their son committing suicide. Of course, it is easy to criticise films which are negative as offerring no hope and films which end happily as unrealistic. The truth may be somewhere in the middle but it is difficult to make into a compelling drama.

Out of Darkness is probably little more than an hour and a half advertisement for clozapine but this viewer was left with one overriding certainty. Diana Ross at her worst still looks better than most of us at our best.

Jacqueline M. Atkdnson, Senior Lecturer in Behavioural Science, Department of Public Health, 2 Llybank Gardens, Glasgow G12 8RZ 